01.1;05.1;06.1

\title{
Проникновение жидкометаллических капель через мембраны на основе одностенных углеродных нанотрубок
}

\author{
() В.М. Губарев ${ }^{1,2}$, М.С. Кривокорытов ${ }^{1}$, В.В. Иванов ${ }^{1}$, В.М. Кривцун ${ }^{1}$, В.В. Медведев ${ }^{1,2}$ \\ ${ }^{1}$ Институт спектроскопии РАН, Москва, Троицк, Россия \\ ${ }^{2}$ Московский физико-технический институт (Национальный исследовательский университет), Долгопрудный, \\ Московская обл., Россия \\ E-mail: gubarev@phystech.edu
}

Поступило в Редакцию 29 ноября 2021 г.

В окончательной редакции 16 декабря 2021 г.

Принято к публикации 22 декабря 2021 г.

\begin{abstract}
Экспериментально определена вероятность проникновения капель разного размера (от $20 \mathrm{~nm}$ до порядка десятков микрометров) сквозь тонкую $(\sim 90 \mathrm{~nm})$ защитную мембрану на основе одностенных углеродных нанотрубок (ОУНТ). Показано, что вероятность проникновения капель с размерами менее $200 \mathrm{~nm}$ сквозь ОУНТ-мембрану составляет $0.4 \%$. Приводятся результаты сравнения эксперимента с данными численного моделирования скорости запыления кремниевых образцов каплями, выполненного при помощи RZLINE-кода. Результаты симуляции находятся в хорошем согласии с результатами эксперимента.
\end{abstract}

Ключевые слова: ОУНТ-мембраны, проникновение капель, RZLINE-код.

DOI: 10.21883/PJTF.2022.06.52207.19091

Экстремальная ультрафиолетовая литография на длине волны $13.5 \mathrm{~nm}$ является ключевой технологией при производстве кремниевых интегральных микросхем с характерным размером менее $8 \mathrm{~nm}$ [1]. Одна из наиболее актуальных задач - разработка источников коротковолнового электромагнитного излучения для ряда приложений: 1) засветка фоторезистивного слоя через проекционную оптику с фотошаблоном [2]; 2) инспекция фотошаблона на наличие дефектов [3]. Применяемые в литографии источники излучения работают на принципах генерации лазерно-индуцированной плазмы. Такие источники обладают высокими значениями мощности, яркости и коэффициента конверсии энергии. Однако их использование вызывает сложности по причине разлета ионов, атомов и капель, загрязняющих оптические элементы [4]. Наличие таких загрязнений на поверхности оптических элементов литографа уменьшает отражательную способность зеркал, что приводит к потере мощности на фоторезистивном слое. Кроме того, загрязнение фотошаблона микрокаплями вызывает появление дефектов в печатных интегральных микросхемах. Поэтому развитие системы защиты оптических элементов литографа крайне востребовано. Одним из решений является использование защитных мембран, к которым предъявляется ряд требований, таких как высокая оптическая прозрачность и механическая стабильность [5]. Перспективным материалом для выполнения защитных функций в экстремальной ультрафиолетовой литографии являются мембраны на основе одностенных углеродных нанотрубок (ОУНТ). ОУНТ-мембраны обладают оптической прозрачностью $T>60 \%$ в диапазоне длин волн $1-20 \mathrm{~nm}(T=80 \%$ на $13.5 \mathrm{~nm})$ и высокими прочностными характеристиками [6]. Однако способность
ОУНТ-мембран останавливать потоки плазмы и микрокапель изучена мало.

В настоящей работе исследуется вероятность проникновения жидкометаллических микро- и нанокапель сквозь ОУНТ-мембраны. Генерация капель в эксперименте осуществлялась в результате взаимодействия лазерного импульса с жидкой In-Sn-мишенью. Анализ количества и размеров падающих и прошедших за ОУНТ-мембрану капель осуществлялся при помощи растровой электронной микроскопии (РЭМ) с последующей обработкой изображений в программе ImageJ [7], что позволило рассчитать вероятность проникновения капель сквозь мембрану.

Также в работе верифицируется RZLINE-код [8], в котором моделируются процессы нагрева металла лазерным излучением, образования излучающей плазмы, образования ударных волн давления в жидкой фазе, приводящие к выбросу капель из мишени. Для этого по РЭМ-снимкам осуществлялся расчет напыления покрытия каплями в терминах „эффективной“ толщины. „Эффективная“ толщина рассчитывалась как отношение полного объема налетевших капель к площади РЭМ-снимка и затем сравнивалась с результатами вычислений по RZLINE-коду.

Принципиальная схема экспериментальной установки показана на рис. 1,a. Для генерации плазмы использовался импульсный дисковый $\mathrm{Nd}: \mathrm{YVO}_{4}$-лазер фирмы EdgeWave $(\lambda=1.064 \mu \mathrm{m}$, энергия импульса $4 \mathrm{~mJ}$, длительность импульса $1.5 \mathrm{~ns}$, частота импульсов $25 \mathrm{kHz}$ ). Излучение фокусировалось на поверхность мишени, размер фокального пятна составлял $60 \mu \mathrm{m}$ (по уровню $\left.1 / e^{-2}\right)$. Мишенью являлся жидкий металл, помещенный в быстро вращающийся $(F=240 \mathrm{~Hz})$ тигель. Такой под- 

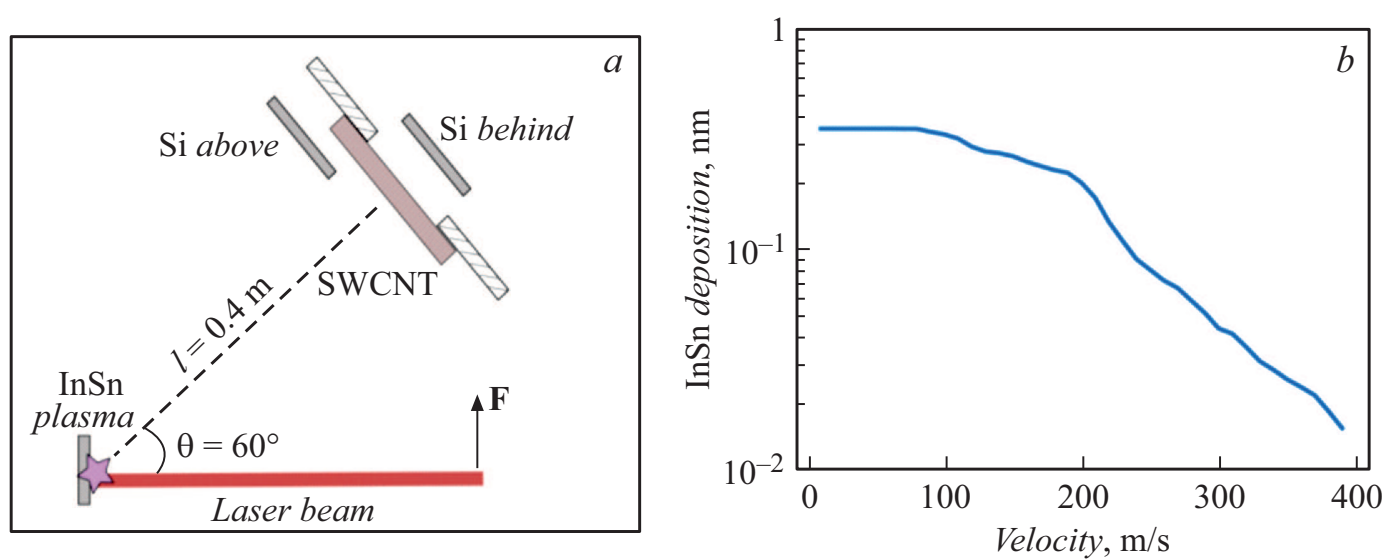

Рис. 1. $a-$ принципиальная схема экспериментальной установки; $b-$ RZLINE-симуляция интегральной толщины покрытия кремния каплями со скоростью, большей заданной, за $1.71 \cdot 10^{9}$ лазерных импульсов.

ход обеспечивал возобновляемую плоскую мишень для всех лазерных импульсов. Материалом мишени являлся эвтектический сплав In и $\mathrm{Sn}\left(m_{\mathrm{In}} / m_{\mathrm{Sn}}=48 \% / 52 \%\right)$. На расстоянии $l=0.4 \mathrm{~m}$ от плазмы под углом $\theta=60^{\circ}$ к нормали поверхности мишени устанавливалась свободно висящая ОУНТ-мембрана с характерной толщиной $d=90 \mathrm{~nm}$. В качестве ОУНТ-мембран использовались коммерчески доступные образцы фирмы Canatu. C целью предотвращения запыления ОУНТ-мембран ионами и атомами плазмы применялись магнитное поле и буферный газ (Ar) при давлении $1.5 \mathrm{~Pa}$. Для характеризации падающих и прошедших через мембрану капель перед и за ОУНТ-мембраной соответственно устанавливались кремниевые образцы-свидетели. После экспозиции образцов каплями в течение $1.71 \cdot 10^{9}$ лазерных импульсов $(19 \mathrm{~h}$ непрерывной работы лазера с частотой $25 \mathrm{kHz}$ ) поверхность $\mathrm{Si}$ исследовалась при помощи РЭМ на различных увеличениях $(10 \mathrm{k}, 1 \mathrm{k}, 100)$. Для репрезентативности выборки для каждого увеличения осуществлялись снимки с десяти различных мест поверхности образцов. С использованием программы обработки изображений ImageJ по РЭМ-снимкам анализировались размер и количество капель на образцах $\mathrm{Si}$. Для увеличений $10 \mathrm{k}, 1 \mathrm{k}, 100$ фиксировались капли диаметром 20-200, 200-2000 и > 2000 nm соответственно. Отношение количества капель, найденных на равных площадях РЭМ-снимков кремниевых образцов, помещенных перед и за защитной ОУНТ-мембраной, определяло вероятность проникновения капель.

На рис. 2, $a$ и $b$ показаны примеры РЭМ-снимков незащищенного кремниевого образца и ОУНТ-мембраны соответственно после экспозиции каплями в течение $1.71 \cdot 10^{9}$ лазерных импульсов. Светлые области на снимках соответствуют In-Sn-каплям. Распределение капель по размерам представлено на рис. 2, c. Из рис. 2, c видно, что количество прилетевших капель на незащищенный ОУНТ-мембраной образец $\mathrm{Si}$ площадью $1 \mu \mathrm{m}^{2}$ уменьшается с увеличением их диаметра.
Количество капель различных размеров, найденных на поверхности образцов $\mathrm{Si}$, приведено в таблице. Из таблицы видно, что вероятность проникновения капель крупных (более $2000 \mathrm{~nm}$ ), средних (200-2000 nm) и малых $(20-200 \mathrm{~nm})$ размеров составляет 67,17 и $0.4 \%$ соответственно. Таким образом, вероятность проникновения капель через ОУНТ-мембрану толщиной $90 \mathrm{~nm}$ убывает с уменьшением их размера. Это может объясняться тем, что уменьшение размера капель, а следовательно, и их массы приводит к уменьшению кинетической энергии. В зависимости от энергии налетающих капель возможны три варианта взаимодействия с ОУНТ-мембраной: 1) пробитие мембраны насквозь; 2) изменение направления движения капли на $180^{\circ}$; 3 ) неупругое столкновение с полной потерей скорости движения. Первый вариант наиболее вероятен для капель крупного размера с высокой кинетической энергией, в то время как второй и третий варианты более вероятны для капель среднего и малого размера.

Отметим, что распределение налетающих капель малого размера было однородным, а после прохождения через ОУНТ-мембрану неоднородным: при сканировании больших площадей образцов только на отдельных РЭМ-снимках наблюдались единичные капли. Это позволяет заключить, что капли проходят через ОУНТ-мембрану без фрагментации.

В предположении, что каждая капля на РЭМ-снимке представляет собой шар, можно рассчитать равномерную „эффективную“ толщину капельного покрытия, образованную за время эксперимента. Рассчитанные значения „эффективной“ толщины покрытия каплями малого, среднего и крупного размеров на образце $\mathrm{Si}$, помещенном перед защитной мембраной, составляют порядка 0.001, 0.061 и $0.262 \mathrm{~nm}$ соответственно. Таким образом, полная „эффективная“ толщина покрытия, напыленного каплями, равна $0.32 \mathrm{~nm}$.

Для теоретического описания скорости напыления был применен RZLINE-код. Рис. 1, $b$ показывает рас- 

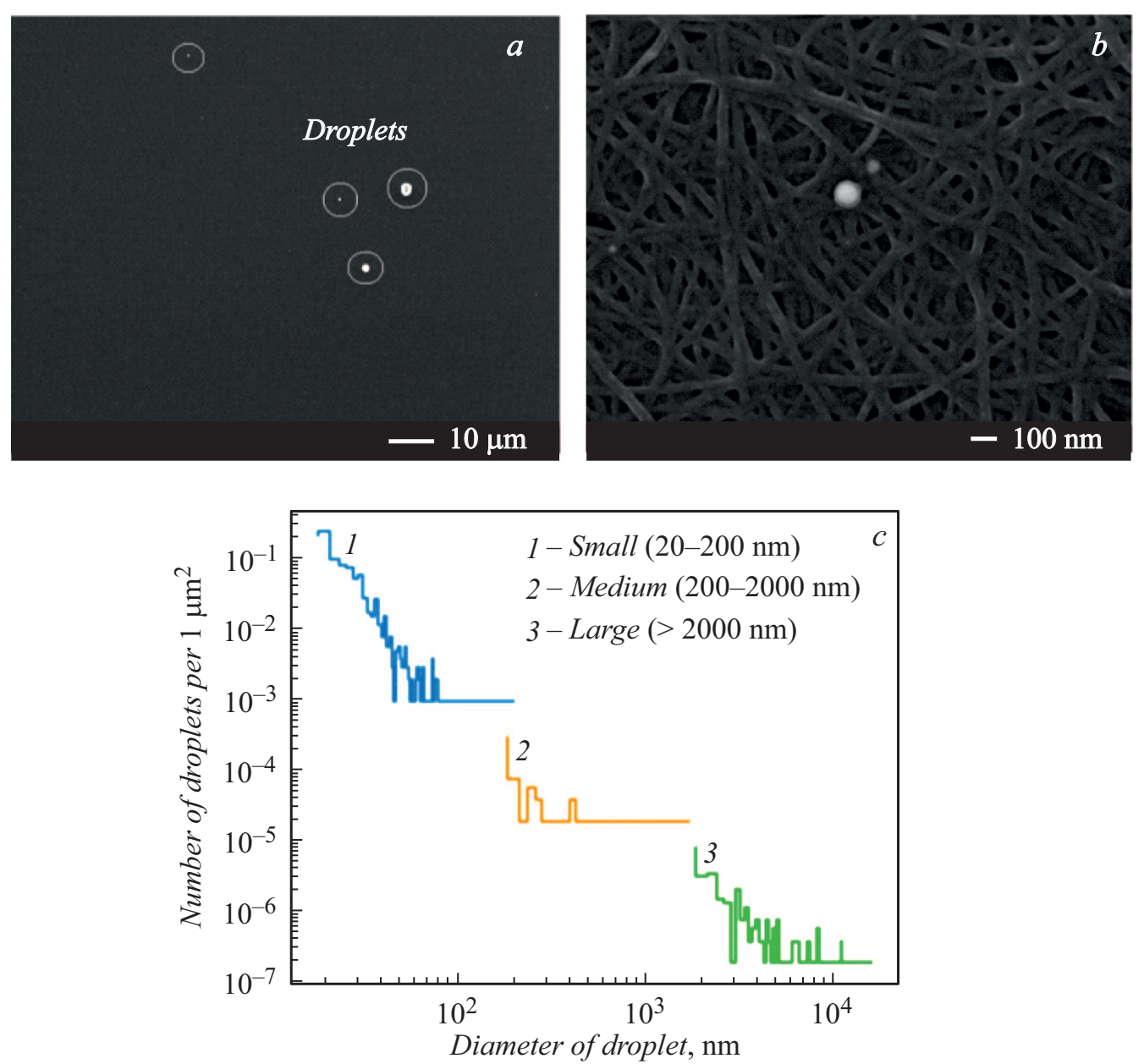

Рис. 2. $a-$ РЭМ-снимок облученного каплями кремниевого образца; $b-$ РЭМ-снимок ОУНТ-мембраны; $c-$ гистограмма распределения частиц по размерам.

Распределение среднего числа капель плазмы на образцах $\mathrm{Si}$, помещенных перед и за защитной ОУНТ-мембраной (в скобках указана площадь РЭМ-снимка)

\begin{tabular}{c|c|c|c}
\hline $\begin{array}{c}\text { Расположение } \\
\text { образцов }\end{array}$ & $\begin{array}{c}\text { Маленькие капли } \\
20-200 \mathrm{~nm} \\
\left(10^{-3} \mathrm{~mm}^{2}\right)\end{array}$ & $\begin{array}{c}\text { Средние капли } \\
200-2000 \mathrm{~nm} \\
\left(0.053 \mathrm{~mm}^{2}\right)\end{array}$ & $\begin{array}{c}\text { Крупные капли } \\
>2000 \mathrm{~nm} \\
\left(5.3 \mathrm{~mm}^{2}\right)\end{array}$ \\
\hline $\begin{array}{c}\text { Перед ОУНТ } \\
\text { За ОУНТ }\end{array}$ & $\begin{array}{c}1078 \\
4\end{array}$ & 35 & 168 \\
\end{tabular}

считанную „эффективную“ толщину покрытия, напыленного жидкой фазой $\mathrm{Sn}+\mathrm{In}$ (каплями) со скоростями выше заданной, осаждающегося на расстоянии $0.4 \mathrm{~m}$ от источника за время эксперимента $\left(1.71 \cdot 10^{9}\right.$ лазерных импульсов). Из рисунка видно, что основной вклад в капельное напыление вносят частицы со скоростями менее $200 \mathrm{~m} / \mathrm{s}$, а максимальная скорость капель не превышает $400 \mathrm{~m} / \mathrm{s}$. При этом полная толщина покрытия составляет порядка $0.34 \mathrm{~nm}$. Отметим, что в RZLINE-коде не учитываются силы поверхностного натяжения, что не позволяет рассчитать распределение капель по их диаметрам, поэтому сравнивается лишь „эффективная“ тол- щина покрытия. Результаты расчетов толщины покрытия находятся в хорошем согласии с экспериментом, что позволяет верифицировать заложенную в RZLINE-коде модель разбрызгивания мишени.

Полученные результаты демонстрируют, что тонкие $(90 \mathrm{~nm})$ ОУНТ-мембраны эффективно подавляют капли размерами 20-200 nm, обеспечивая вероятность проникновения $0.4 \%$. Показано, что вероятность проникновения капель возрастает при увеличении их размера. Представлены расчеты кода RZLINE скорости напыления покрытий в терминах „эффективной“ толщины, которые находятся в хорошем согласии с экспериментом. 


\section{Конфликт интересов}

Авторы заявляют, что у них нет конфликта интересов.

\section{Список литературы}

[1] M.S. Lawrence, Adv. Opt. Technol., 10 (2), 85 (2021). DOI: $10.1515 /$ aot-2021-0018

[2] H. Mizoguchi, H. Nakarai, T. Abe, H. Tanaka, Y. Watanabe, T. Hori, T. Kodama, Y. Shiraishi, T. Yanagida, G. Soumagne, T. Yamada, T. Saitou, J. Photopolym. Sci. Technol., 32 (1), 77 (2019). DOI: 10.2494/photopolymer.32.77

[3] A. Tchikoulaeva, H. Miyai, T. Kohyama, K. Takehisa, H. Kusunose, Proc. SPIE, 11323, 113231K (2020). DOI: $10.1117 / 12.2557858$

[4] M. Brandstätter, M.M. Weber, R.S. Abhari, J. Appl. Phys., 129 (23), 233306 (2021). DOI: 10.1063/5.0050927

[5] R. Lafarre, R. Maas, Proc. SPIE, 11609, 1160912 (2021). DOI: $10.1117 / 12.2587058$

[6] V. Gubarev, V. Yakovlev, M. Sertsu, O. Yakushev, V. Krivtsun, Y. Gladush, I. Ostanin, A. Sokolov, F. Schäfers, V. Medvedev, A. Nasibulin, Carbon, 155, 734 (2019). DOI: $10.1016 /$ j.carbon.2019.09.006

[7] C.A. Schneider, W.S. Rasband, K.W. Eliceiri, Nature Methods, 9 (7), 671 (2012). DOI: 10.1038/nmeth.2089

[8] K. Koshelev, V. Ivanov, V. Medvedev, V.M. Krivtsun, V.G. Noivkov, A.S. Grushin, J. Micro/Nanolithography, MEMS, and MOEMS, 11 (2), 021112 (2012).

DOI: 10.1117/1.JMM.11.2.021112 